\title{
Histopathology Study of the Platelet Rich Plasma on the Wound Healing in Rabbits
}

\author{
Ammar Maatoq Hashim ${ }^{1}$, Hayder Hussein Abd ${ }^{2}$, Montaser Mohammede Hellal ${ }^{3}$ \\ ${ }^{1}$ Research Scholar, Department of Surgery, College of Veterinary Medicine, Al-Basrah University, Al Basrah, Iraq, \\ ${ }^{2}$ Research Scholar, Department of Surgery, College of Veterinary Medicine, Al-Qassim green University, \\ Baghdad, Iraq, ${ }^{3}$ Research Scholar, Department of Surgery, College of Veterinary Medicine, Tikrit University, \\ Tikrit, Iraq
}

\begin{abstract}
The study aimed to evaluate the beneficial effect of platelets rich plasma (PRP) on wound heal in rabbit. Eighteen healthy male adult rabbit were used they were randomly divided into two equal groups (control group 9, treated group 9). Under aseptic technique $3 \mathrm{~cm}$ skin incision was made in the back (dorsal) of animal by scalpel, after that the incision was sutured immediately by silk suture materials 0.2 USP used simple interrupted technique treated group receive immediately post operation PRP $(1 \mathrm{ml})$ was injected at the site of the wound, while control group left without treatment. Skin healing process follow up 1,2 and 3 weeks post operation by histopathological examination, the result display in treated group on the first week post operation development of granulation tissue with epithelial regeneration. 2 weeks post operation show intense inflammatory infiltration with desquamation tissue, granulation tissue and new blood vessels formation. 3 weeks post operation showed proliferation of fibroblast with deposition of collagen, while in control group histopathological examination in the first week show intense inflammatory infiltrate with desquamated tissue and hemorrhage, 2 weeks post operation show area of intensive acute inflammatory infiltrate, 3 weeks post operation show area of chronic inflammatory infiltrate with tissue debris and giant cells, the healing of treated group better than control group.
\end{abstract}

Keywords: Platelet Rich Plasma, Wound Healing, Rabbits.

\section{Introduction}

Skin is that the largest and most visible organ of the body, comprising up to $15-20 \%$ of the whole weight. It receives around one third of the body's blood offer at a rate of three hundred $\mathrm{mls} /$ minute. Traditional skin consists of 2 layers: stratum and stratum. Underneath the stratum lies the connective tissue (or hypodermis), a layer of loose animal tissue. The skin has six major functions. They're protection, thermoregulation, elimination of waste product, synthesis of $\mathrm{D}$, sensation and communication ${ }^{(1)}$.

\section{Corresponding Author:}

\section{Hayder Hussein Abd}

Research Scholar, Department of Surgery, College of Veterinary Medicine, Al-Qassim green University, Baghdad, Iraq

e-mail: haideralomary@yahoo.com
Wound may be a consequence of wound fatal if not treated timely and square measure aggravated by secondary microorganism infection. Improper development of animal tissue tissues, angioblasts and fibroblasts additionally the facts of wound complications ${ }^{(2)}$. There square measure several factors which will have an effect on wound healing that interfere with one or a lot of phases during this method, therefore inflicting improper or impaired tissue repair. Wounds that exhibit impaired healing, as well as delayed acute wounds and chronic wounds, usually have didn't progress through the conventional stages of healing. Such wounds often enter a state of pathologic inflammation because of a deferred, incomplete, or uncoordinated healing method. Most chronic wounds square measure ulcers that square measure related to ischaemia, diabetes, blood vessel stasis illness, or pressure.

Sometimes the healing of wounds square measure 
delayed and therefore the success of the wound healing another extra taxes to the homeowners. Numerous biomaterials, proteins, antibiotics, vitamins and minerals come back to the scene because the angel to accelerate the repair of the wound by stimulating growing, fibroblastosis and epithelialization of wound ${ }^{(2,3,4,5)}$. Platelets are incontestible to be the natural supply of many growth factors and cytokines that promote blood clotting, tissue repair, and therefore the method of bone mineralization $^{(6,7,8,9)}$. Platelet-rich plasma (PRP) is that the second price effective supply of protein that effectively hemostasizes and stimulates cellular regeneration ${ }^{(11,12,13)}$. Application of PRP may be a new approach for tissue regeneration used as gel formulation containing completely different bioactive substances ${ }^{(10,14)}$. PRP gel exhibits fast animal tissue differentiation and enhance organization of dermal scleroprotein in contemporary wound $^{(15)}$. Degranulation of platelets causes unleash of remodeling growth factor- $\beta 1$ (TGF- $\beta 1$ ), platelet-derived protein (PDGF), fibrinogen, epidermic protein (EGF), histamine, and hydrolytic enzymes ${ }^{(16,17)}$. These square measure concerned within the angiogenic cascade that assists in arduous and soft tissue wound healing ${ }^{(7,9)}$.

\section{Materials and Method}

Experimental Animals: A total of 18 apparently healthy adult local breed male rabbits were recruited for this study. All animals were evaluated clinically by physical examination before initiation of the experiments. The animals were housed in metal cages $30 / 70 / 60 \mathrm{~cm}$ in an air- conditioned room in the animal house along the period of the experiments. They were received free accesses to water and food. The animals were left two weeks for adaption with experimental condition with using of prophylactic drug, the animals were divided into two equal groups (control and treatment groups).. Control group left without treatment, Specimens from the injured skin were taken three animals per group at 1,2 and 3 weeks postoperative for histopathological examination to evaluate the progress of wound healing process.

Surgical Procedure: Surgical operations were made under general anesthesia by a mixture of xylazine ketamine given by IM injection $(50 \mathrm{mg} / \mathrm{kg}$. B.W. ketamine, and $10 \mathrm{mg} / \mathrm{kg}$. B.W. xylazine) ${ }^{(11)}$. The operation site was prepared aseptically. Skin incision $(3 \mathrm{~cm})$ on the back (dorsal) was made by use of scalpel, then the incision sutured immediately using silk suture material 0.2 USP by using simple interrupted technique.
Treated group receive immediately post operation PRP $(1 \mathrm{ml})$ was injected at the site of the wound, while control group left without treatment.

PRP Preparation: 3ml of Blood were collected from each rabbits using a $3 \mathrm{ml}$ disposable syringe. The samples were transferred into anticoagulant tubes containing $0.35 \mathrm{ml}$ of $10 \%$ sodium citrate. The blood was initially centrifuged at $160 \mathrm{rpm}$, for ten minutes at room temperature. After the first centrifugation, two layers were observed in each sample. A red lower layer that consists of packed red blood cells and an upper strawyellow layer that contains plasma component. The upper surface of packed red blood cells called Buffy coat is rich in platelets and leukocytes. Plasma and buffy coat were transferred to new sterile tubes. The retained component of blood samples was centrifuged again at $160 \mathrm{rpm}$ for two minutes to obtain more concentrated platelets. Then, the plasma and Buffy coat was centrifuged for the second round at $400 \mathrm{rpm}$, for 15 minutes. Two layers eventually appeared: the upper two thirds of the sample was designated as platelet poor plasma (PPP) and was discarded, on the other hand, the lower third was PRP (Fig5).Moreover, the platelets were activated by $0.05 \mathrm{ml}$ of $10 \%$ calcium chloride solution to each $1 \mathrm{ml}$ of PRP (Maghsoudi et al.,2015).

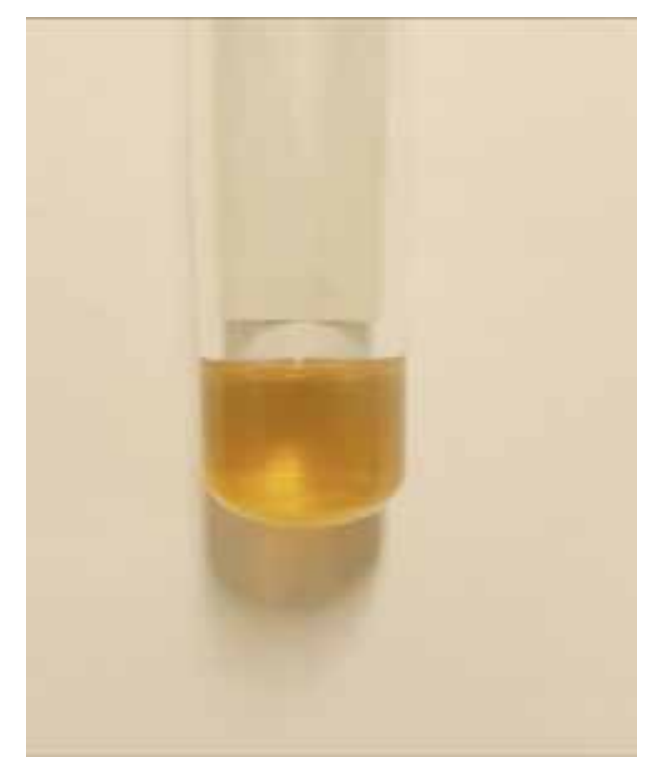

Figure (1): PRP

\section{Results}

1. Control group: Shows section of skin of control positive animals reveals the site of surgical incision after one week containing intense inflammatory infiltrate (INF), with desquamated tissue (DE) and 
hemorrhage $(\mathrm{H})$. Skin of control positive group after two weeks shows area of intensive acute inflammatory infiltration (INF) at the site of skin wound. Skin of control positive group after three weeks shows area of intensive chronic inflammation (CIN) at the site of skin wound with tissue debris (TD). And in another section of Skin of control positive group after three weeks shows area of intensive chronic inflammation (CIN) at the site of skin wound with giant cells (GS).

2. PRP treated group: Section of Skin of PRP treated group after one week shows development of granulation tissue at the site of skin wound figure
Medico-legal Update, April-June 2021, Vol. 21, No. 2

1311

(1) and another section of Skin of PRP treated group after one week shows development of granulation tissue (GT) at the site of skin wound with epithelial regeneration (ER) figure (2). the section of skin of PRP treated animals reveals the site of surgical incision after 2 week containing intense inflammatory infiltrate (INF), with desquamated tissue (DE) and granulation tissue (Gr) new generated blood vessels figure (3). Skin of PRP treated group after three weeks shows proliferation of fibroblast (FB) with collagen deposition (CD) at the site of skin wound figure (4) and another slide shows proliferation of fibroblast (FB) with collagen deposition (CD) at the site of skin wound figure (5)

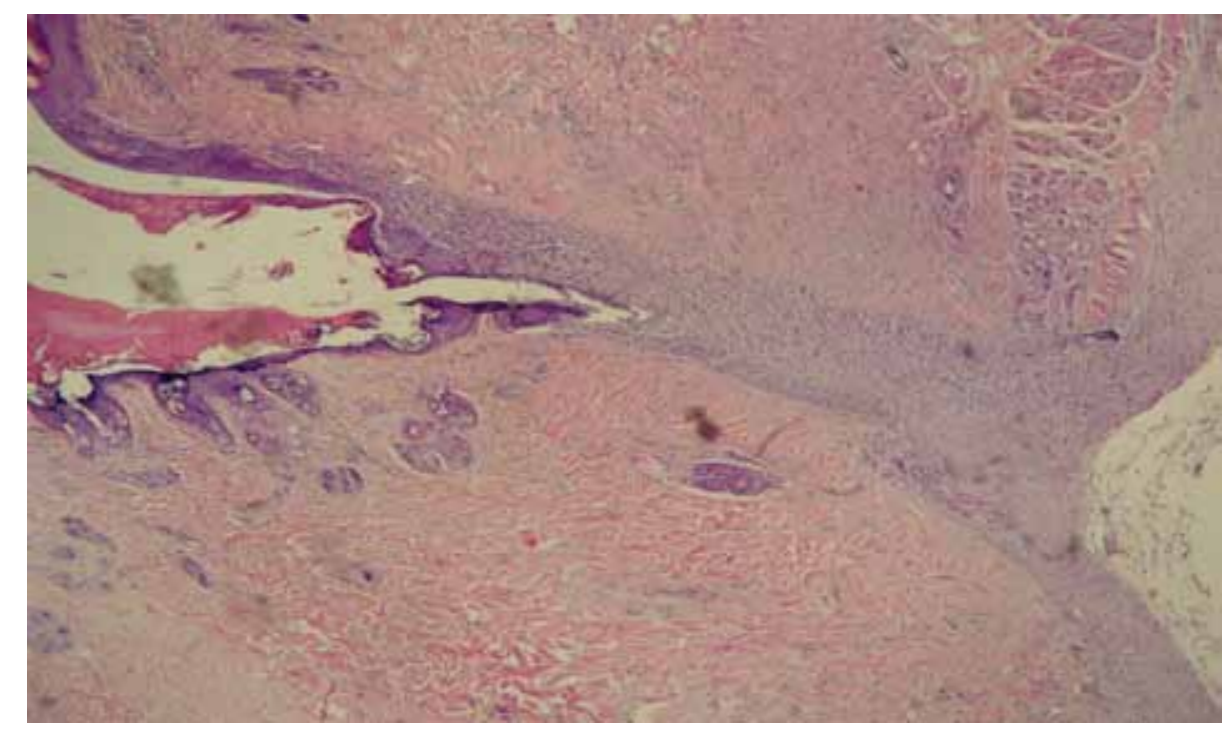

Figure (1) Skin of PRP treated group after one weak shows development of granulation tissue at the site of skin wound (GT) H \& E 50X

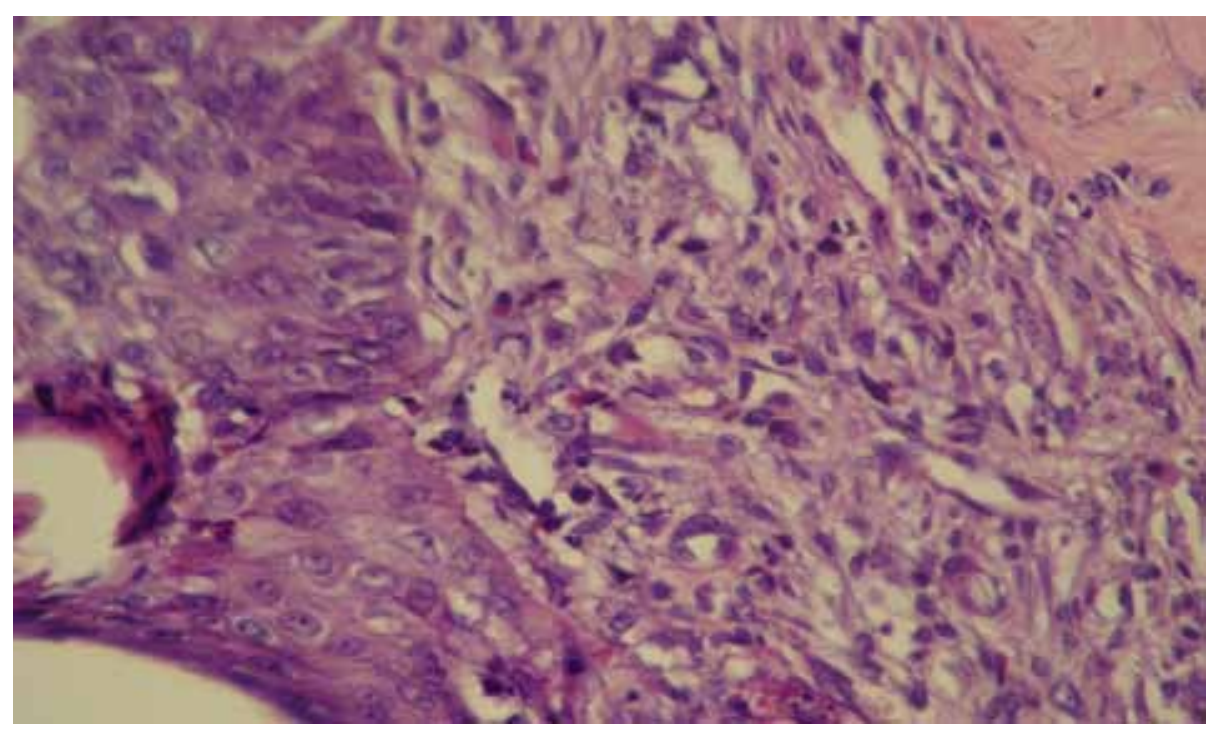

Figure (2) Skin of PRP treated group after one weak shows development of granulation tissue (GT) at the site of skin wound with epithelial regeneration (ER) H \& E 500X 




Figure (3): Section of skin of PRP treated animals reveals the site of surgical incision after 2 week containing intense inflammatory infiltrate (INF), with desquamated tissue (DE) and granulation tissue (Gr) new generated blood vessels A) 50 H \& E

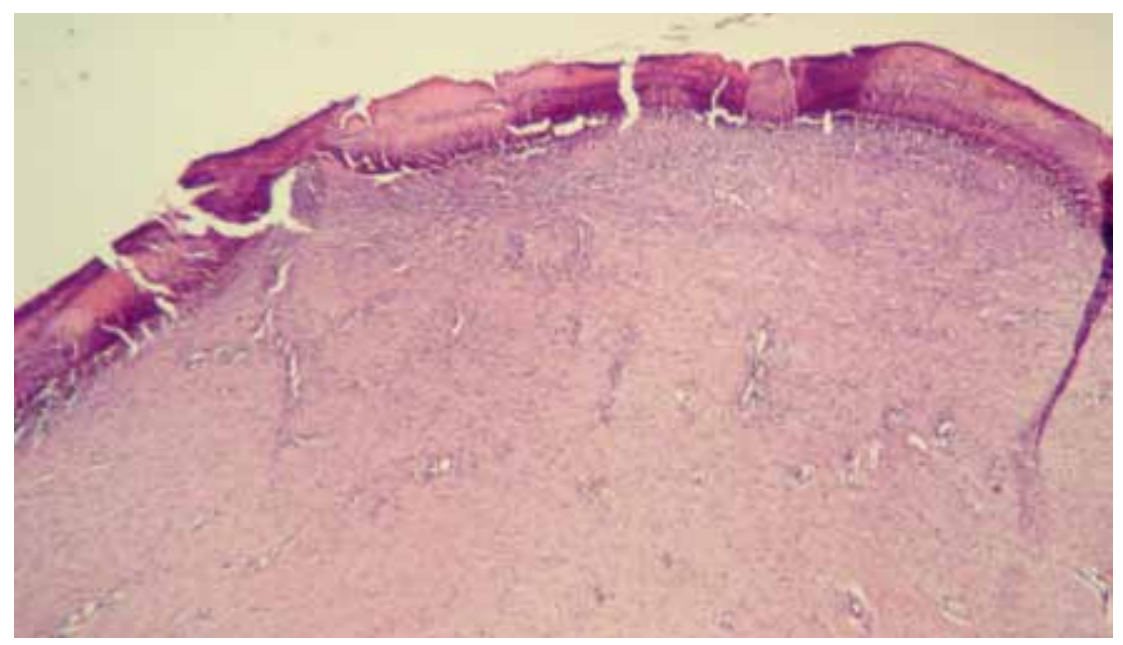

Figure (4) Skin of PRP treated group after three weeks shows proliferation of fibroblast (FB) with collagen deposition (CD) at the site of skin wound $\mathrm{H} \& \mathrm{E} 50 \mathrm{X}$

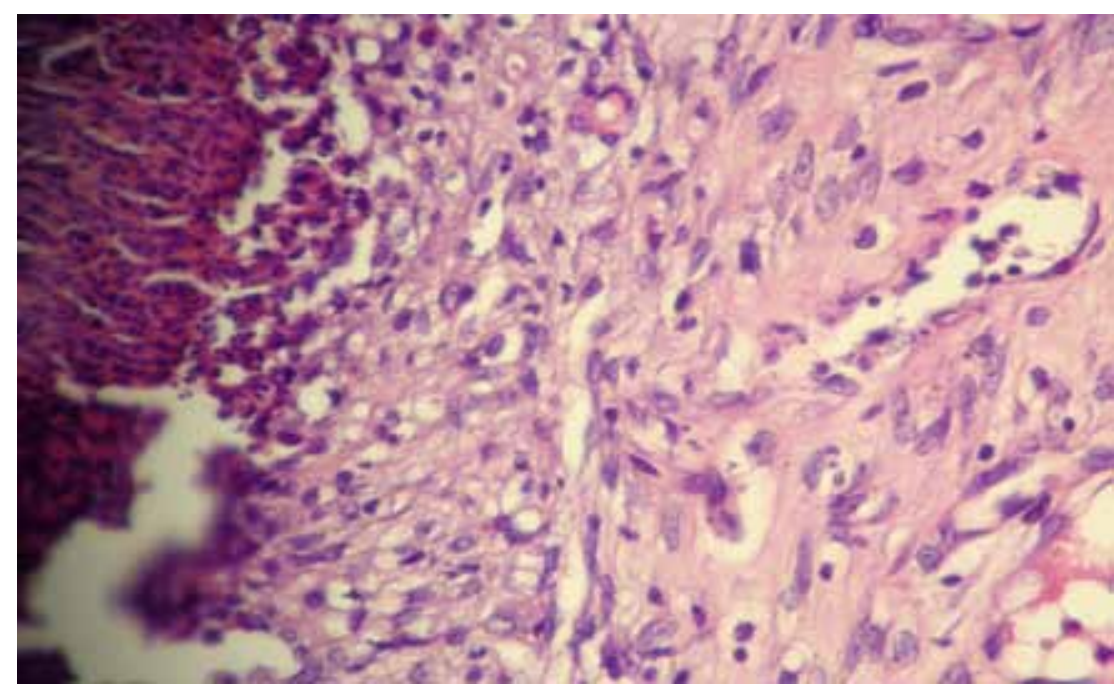

Figure (5) Skin of PRP treated group after three weeks shows proliferation of fibroblast (FB) with collagen deposition (CD) at the site of skin wound $\mathrm{H} \& \mathrm{E} 500 \mathrm{X}$ 


\section{Discussion}

The wound healing growth factors which are activated by platelets is greater to continue this process more quickly and smoothly. When these factors are at the wound site, recruitment and differentiation of cells in tissue repair increase and so tissue repair occurs more quickly and well ${ }^{(20)}$. is a process which consists of hemostasis, inflammation, proliferation, maturation and remodeling. The effect of growth factors which are activated by platelets is greater to continue this process more quickly and smoothly. When these factors are at the wound site, recruitment and differentiation of cells in tissue repair increase and so tissue repair occurs more quickly and well (20). (Platelet-rich plasma is defined as a platelet concentration of at least 10,00,000 platelets/ $\mu \mathrm{L}$ in $5 \mathrm{ml}$ of plasma. It contains a $3-5$ fold increase in the concentration of growth factors. 10 Proteomic studies have shown that platelets contain over 800 proteins with numerous post-translational modifications, resulting in over 1,500 proteinbased bioactive factors ${ }^{(21)}$. In our study the treated group at 7 days post operation showed development of granulation tissue at site of incision with epithelial regeneration this agreement with $^{(22)}$ who explained that wounds treated with PRP gel has more rapid epithelial differentiation and enhanced organization of dermal collagen compared to control groups in horses. in present study in treated group 2 weeks post operation showed intense inflammatory cells and granulations tissue this agreement with ${ }^{(23)}$. In a study on dogs performed. it revealed of PRP which was injected into the wound site was investigated on wound healing and then it was reported to have positive effects on granulation formation, collagen deposition, and re-epitheliali-zation. The recent study achieved to show the effect of PRP on the healing of acute wounds in rabbits displayed that the PRP treated group enhanced angiogenisis at the wound beds as compared to control group(24) and this has agreement with the present study in an experimental study on rabbits conducted by Ostvar et al. (24), PRP was topically applied to the lesions created on the backs of animals and then it was reported that reepithelialization, angiogenesis, and collagen deposition were statistically significantly increased compared to the control group, this agreement with the our study. It has been reported in different studies that PRP accelerated the inflammatory process ${ }^{(25)}$. This agreement with our study the treated group at 2 weeks post operation showed high inflammatory process by intense inflammatory infiltrate at site of injury. While ${ }^{(26)}$ Application of PRP in cutaneous regeneration and wound healing in dogs, who revealed that there were no significant differences between median of epithelialization, inflammatory cell infiltration, presence of dermal granulation tissue, fibroblast arrangement, fibroblast proliferation, collagen deposition in the both of treated and non-treated wounds and this disagreed with our study because we found wide differentiation between treated and control group in treated group appear better wound healing by high inflammatory cells, collagen deposition, angiogenesis, a granulation tissue, re-epithelializatin and high proliferation of fibroblast.

\section{Conflict of Interest: None}

\section{Funding: Self}

Ethical Clearance: Not required

\section{References}

1. Su DM, Zhao JH, Huang ZY. Application of artificial skin combined with external fixator in the treatment of severe open fractures of legs. Zhongguo gu shang= China journal of orthopaedics and traumatology. 2012 Jun 1;25(6):520-2.

2. Gönül B, Kaplan B, Bilgihan K, Budak MT. Effects of epidermal growth factor in artificial tear on vitamin $\mathrm{C}$ levels of corneal wounded eye tissues. Eye. 2001 Mar; 15(2):213-6.

3. Thompson C, Fuhrman MP. Nutrients and wound healing: still searching for the magic bullet. Nutrition in clinical practice. 2005 Jun; 20(3):33147.

4. Abdelmalek, M. and Spencer, J., 2006. Retinoids and wound healing. Dermatologic surgery, 32(10), pp.1219-1230.

5. Tsourdi E, Barthel A, Rietzsch H, Reichel A, Bornstein SR. Current aspects in the pathophysiology and treatment of chronic wounds in diabetes mellitus. BioMed research international. 2013 Jan 1;2013.

6. Dugrillon A, Klüter H. Current use of platelet concentrates for topical application in tissue repair. Transfusion Medicine and Hemotherapy. 2002;29(2):67-70.

7. Anitua E, Andia I, Ardanza B, Nurden P, Nurden AT. Autologous platelets as a source of proteins for healing and tissue regeneration. Thrombosis and haemostasis. 2004;91(01):4-15.

8. Roldán JC, Jepsen S, Miller J, Freitag S, Rueger 
DC, Açil Y, Terheyden H. Bone formation in the presence of platelet-rich plasma vs. bone morphogenetic protein-7. Bone. 2004 Jan 1;34(1):80-90.

9. Nikolidakis D, Jansen JA. The biology of plateletrich plasma and its application in oral surgery: literature review. Tissue Engineering Part B: Reviews. 2008 Sep 1;14(3):249-58.

10. Albanese A, Licata ME, Polizzi B, Campisi G. Platelet-rich plasma (PRP) in dental and oral surgery: from the wound healing to bone regeneration. Immunity \& Ageing. 2013 Dec 1;10(1):23.

11. Robson MC. The role of growth factors in the healing of chronic wounds. Wound repair and regeneration. 1997 Jan;5(1):12-7.

12. Bhanot S, Alex JC. Current applications of platelet gels in facial plastic surgery. Facial plastic surgery. 2002 Feb 1;18(1):27-34.

13. Marx RE. Platelet-rich plasma: evidence to support its use. Journal of oral and maxillofacial surgery. 2004 Apr 1;62(4):489-96.

14. Garcia RV, Gabrielli MA, Hochuli-Vieira E, Spolidorio LC, Filho JG, Neto FA, de Cardoso LA, Shibli JA. Effect of platelet-rich plasma on periimplant bone repair: a histologic study in dogs. Journal of Oral Implantology. 2010 Aug;36(4):281 90.

15. DeRossi R, Coelho AC, Mello GS, Frazílio FO, Leal CR, Facco GG, Brum KB. Effects of platelet-rich plasma gel on skin healing in surgical wound in horses. Acta cirúrgica brasileira. 2009 Aug;24(4):276-81.

16. P. Harrison andE.M. Cramer, Platelet -granules. Blood Reviews, 7,52-62, 1996.

17. S. Kliche andJ. Waltenberg, VEGF receptor signaling and endothelial function. IUBMB Life, 2001. 52, 61-66.

18. Mooren RE, Dankers AC, Merkx MA, Bronkhorst EM, Jansen JA, Stoelinga PJ. The effect of plateletrich plasma on early and late bone healing using a mixture of particulate autogenous cancellous bone and Bio-Oss ${ }^{\circledR}$ : an experimental study in goats.
International journal of oral and maxillofacial surgery. 2010 Apr 1;39(4):371-8.

19. Foster TE, Puskas BL, Mandelbaum BR, Gerhardt MB, Rodeo SA. Platelet-rich plasma: from basic science to clinical applications. The American journal of sports medicine. 2009 Nov;37(11):225972.

20. Boswell SG, Cole BJ, Sundman EA, Karas V, Fortier LA. Platelet-rich plasma: a milieu of bioactive factors. Arthroscopy: The journal of arthroscopic \& related surgery. 2012 Mar 1;28(3):429-39.

21. Rafael DR, Anna CA, Gisele S. MEffects of platelet-rich plasma gel on skin healing in surgical wound in horses.Acta Cirúrgica Brasileira. 2009. 24 (4) 276-281.

22. Jee CH, Eom NY, Jang HM, Jung HW, Choi ES, Won JH, Hong IH, Kang BT, Jeong DW, Jung DI. Effect of autologous platelet-rich plasma application on cutaneous wound healing in dogs. Journal of veterinary science. 2016 Mar 1;17(1):7987.

23. Ostvar O, Shadvar S, Yahaghi E, Azma K, Fayyaz AF, Ahmadi K, Nowrouzian I. RETRACTED ARTICLE: Effect of platelet-rich plasma on the healing of cutaneous defects exposed to acute to chronic wounds: a clinico-histopathologic study in rabbits. Diagnostic pathology. 2015 Dec 1;10(1):85.

24. Quarteiro ML, Tognini JR, de Oliveira EL, Silveira I. The effect of platelet-rich plasma on the repair of muscle injuries in rats. Revista Brasileira de Ortopedia (English Edition). 2015 Sep 1;50(5):58695.

25. Sardari K, Emami MR, Kazemi H, Movasagi AR, Goli AA, Lotfi A, Malekzadeh S. Effects of plateletrich plasma (PRP) on cutaneous regeneration and wound healing in dogs treated with dexamethasone. Comparative Clinical Pathology. 2011 Apr 1;20(2):155-62.

26. Maghsoudi O, Shirazi SH, Abarkar M, Anvar SA. standardization and Moodification Techniques of Phatelet-Rich Plasma (PRP) Preparation in Rabbit. International Clinical Pathology Journal. 2015 Sep $12 ; 1$. 